\title{
A formação médica segundo uma pedagogia de resistência
}

artigos

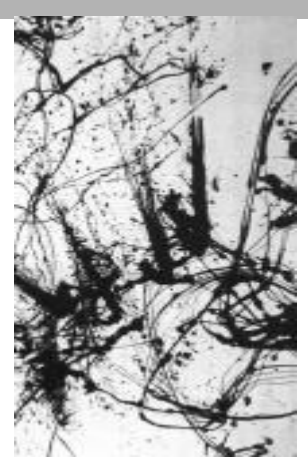

Ondina Pena Pereira ${ }^{1}$

Tãnia Mara Campos de Almeida ${ }^{2}$

PEREIRA, O. P.; ALMEIDA, T. M. C. Medical education according to a resistance pedagogy, Interface Comunic., Saúde, Educ., v.9, n.16, p.69-79, set.2004/fev.2005.

This article discusses the current state of healthcare education practices and the fragmented vision they offer of the human being, in that they reduce man to a technical and passive body, a mere object of invasive and medicinal intervention. By excluding from their horizon any reference to man's holistic dimension, these practices fail to deal with the social, cultural, political and psychological injunctions that are found in the development of states of heath or sickness. Furthermore, they disregard the subjectivity of the players involved in the production of sickness and of cure itself, also disregarding their own role as craftsmen shaping a unique type of modern individualistic subjectivity. Thus, the article presents a critical view of the overly biological attitude of the dominant teachings, a view that has developed even within some of the healthcare schools and that encompasses the learnings provided by the humanities. Finally, the article presents theoretical and methodological guidelines for the development of an alternative model of medical education, one that would be capable of regarding human beings holistically, recognizing the uniqueness of each individual and their condition as subjects of their own history, breaking away from the conservative, authoritarian and market-oriented structures of current medical education.

KEY-WORDS: Medical education; critical pedagogy; body and intercultural dialogue.

Discute-se, neste artigo, o estado atual das práticas educativas relativas à saúde e a visão fragmentária que estas têm do ser humano, reduzindo-o a um corpo técnico, passivo, objeto de intervenções invasivas e por medicamentos. Ao excluírem de seu horizonte de referência a dimensão totalizante do ser humano, tais práticas deixam de abordar as injunções sociais, culturais, políticas e psicológicas presentes no desenvolvimento dos estados de saúde/doença. Além disto, desconhecem a subjetividade dos atores envolvidos na produção da doença e da própria cura, bem como desconhecem a si próprias enquanto artífices da modelagem de um tipo próprio da subjetividade individualista moderna. Apresenta-se, assim, uma visão crítica da excessiva biologização dos ensinamentos dominantes, surgida no interior mesmo de algumas escolas de saúde e que se favorece do saber das Ciências Humanas. Por fim, indicam-se diretrizes teórico-metodológicas para uma proposta alternativa de educação médica que considere o ser humano na sua globalidade, alteridade e condição de sujeito da sua própria história, rompendo com as estruturas conservadoras, autoritárias e mercadológicas da formação médica atual.

PALAVRAS-CHAVE: Educação médica; pedagogia crítica; corpo e diálogo intercultural.

\footnotetext{
${ }^{1}$ Professora, Universidade Católica de Brasília; Coordenadora do grupo de pesquisa do CNPq "Pedagogias de Resistência". <ondinapena@brturbo.com>

${ }_{2}^{2}$ Professora, Universidade Católica de Brasília; Coordenadora do grupo de pesquisa do CNPq "Pedagogias de Resistência". $<$ tmara@pos.ucb.br>
} 
Introdução ${ }^{3}$

A necessidade e urgência da realização de mudanças no setor de saúde, amplamente reconhecidas no país, atingiu o setor da educação médica que tem recentemente se empenhado na construção de um modelo éticohumanista buscando, para tanto, a efetiva inserção das Ciências Humanas em seu saber.

É bastante conhecido o crescimento do aparelho formador em medicina nas últimas três décadas, sobretudo na América Latina e no Brasil, com a conseqüente expansão do número de professores e alunos. Porém, a formação desses atores é pouco estudada, sendo precárias as informações a esse respeito. Iniciamos, então, uma pesquisa ${ }^{4}$ que busca conhecer tal realidade e volta-se para conteúdos inovadores na formação dos médicos, assim como para formas alternativas de repasse desses conteúdos.

o locus de observação da pesquisa vem sendo o curso de medicina, criado pela Escola Superior de Ciências da Saúde e pela Fundação de Ensino e Pesquisa em Ciências da Saúde da Secretaria de Estado de Saúde do Distrito Federal (DF) em 2001, por possuir um projeto pedagógico original e interdisciplinar. Sua abordagem visa superar as contradições do modelo biologicista e tecnificante, ao enfocar o ser humano também em suas dimensões psico-sócio-culturais. Além disto, o curso pretende cumprir um relevante papel social, comprometido com o aumento da qualidade de vida $e$ a promoção da saúde em todas as comunidades em que atua.

São os saberes e as práticas inovadoras, críticos à representação do ser humano enquanto mera complexidade biológica, que nos auxiliarão a identificar e a compreender determinados processos de subjetivação existentes na formação desses profissionais, bem como desvendar melhor um tipo próprio de individuação e de subjetividade ocidental moderna que se esboçam no fim do século XX e começo do século XXI. O presente artigo, portanto, é parte da reflexão inicial da referida pesquisa.

Em sua primeira seção, apresentamos os traços ideológicos da história do ensino da medicina no país. Na seção seguinte, elaboramos uma crítica do corpo enquanto conhecimento biológico e fragmentado, reduzido a um corpo técnico, passivo, objeto de intervenções invasivas e medicamentosas. Em seguida, por intermédio do diálogo intercultural e de reflexões filosóficas, propomos um outro olhar sobre os corpos presentes no encontro terapêutico, ou seja, o do médico e o do doente. Por fim, servindonos de diretrizes teórico-metodológicas do curso de medicina do Governo do Distrito Federal (GDF), discutimos atos pedagógicos que consideram o ser humano na condição de sujeito de sua própria história, buscando romper com estruturas conservadoras, autoritárias e mercadológicas da formação médica atual.

Breve histórico sobre a formação médica

A formação do profissional da saúde vem se limitando, predominantemente, às funções de mera reprodução de conteúdos de natureza anátomo-fisiológicas e das práticas médicas dominantes. Enquanto tal, não dá lugar ao questionamento dos aspectos formais e ideológicos constitutivos das ações educativas e práticas médicas - elementos capazes de 
${ }^{5}$ Os fundamentos da relevância encontramse nas novas orientações nacionais e internacionais para a educação médica, definidas nas últimas conferências internacionais de educação médica (Edimburgo 1988: Havana 1991 Edimburgo, 1993), do Encontro Americano de Educação Médica (Punta Del Este, 1992), bem como do Relatório Geral da Avaliação do Ensino Medico no Brasi (1991-97). Vale ainda lembrar o pressuposto da Organização PanAmericana de Saúde que afirma serem a educação médica $e$ a medicina práticas sociais, cujos fins e meios têm de ser definidos historicamen te, considerando-se as necessidades de cada sociedade. As doenças podem não ser diferentes, mas existirão diferenças na ocorrência das mesmas nas prioridades

regionais e na estrutur cultural e social, que levarão a diferenças na prática médica $e$ sanitarista. interferir na consciência dos atores e de repercutir em suas intervenções, na melhoria dos serviços e nas condições de vida da população.

Ora, tal formação está intimamente relacionada à estrutura econômica hegemônica na sociedade na qual se desenvolve e estabelece vínculos com outros processos. Assim, as condições históricas de produção definem, em grande parte, a importância, o lugar, as instituições e a forma de a medicina se realizar.

Em um dos poucos livros que recompõem a história da educação médica no Brasil (Almeida, 1999), o autor investiga a relação entre educação médica e serviços de saúde, bem como analisa as possibilidades de mudanças no ensino diante das reformas com a implantação do Sistema único de Saúde e a fixação da perspectiva mercadológica na área.

Para esclarecer o binômio medicina-sociedade em três marcantes períodos históricos da América Latina, fundamenta-se em três conjuntos de elementos explicativos propostos pelo esquema analítico de Ferreira (1988): a tríade "quantitativo-qualitativo-relevância" - dimensões, ao mesmo tempo, interdependentes e autônomas, conforme é mostrado a seguir.

$\mathrm{Na}$ década de 1960, a ênfase na carência de médicos levou a um enfoque quantitativo do problema e ao predomínio do modelo tradicional: número de escolas, proporção professor-aluno, cargas horárias curriculares e disciplinares, número de leitos hospitalares por aluno, número de alunos por cadáver ou por microscópio, entre outros indicadores. Nesse quadro, tiveram lugar as mudanças superficiais da educação, que se concentraram nas relações técnicas entre os agentes e o processo de ensino, canalizadas em projetos de extensão voltados para áreas de demonstração ou "laboratórios de comunidade".

Nas décadas de 1970 e 1980, a preocupação centrou-se nas dimensões qualitativas da educação, sob o prisma da excelência técnica. A ênfase recaiu nas ações pedagógicas voltadas à melhoria da qualidade do ensino e nas ações organizacionais no âmbito universitário, voltadas ao aprendizado prático nos serviços hospitalares e ambulatoriais. Houve uma certa reinterpretação das bases conceituais do modelo tradicional, tendo com isto atingido as relações sociais, com o estabelecimento de novos critérios de convivência entre os sujeitos e variadas articulações entre ensino-serviçoscomunidade.

Mais radical em sua concepção, o item relevância introduziu a concepção de qualidade enquanto condição que responde globalmente às necessidades da população, deixando de ser sinônimo de excelência técnica. Haja vista que esta, elevada ao mais alto grau de sofisticação científico-tecnológica, desconsidera critérios de acessibilidade e cobertura populacional. Encontram-se aqui as mudanças recentes que propõem uma nova ordem na formação de médicos e nas suas relações com a estrutura socioeconômica. Assim, dá atenção ao contexto, aos determinantes histórico-sociais, ao sentido social da produção do conhecimento e à diversidade de paradigmas, causando forte impacto sobre as relações políticas entre os sujeitos e atores institucionais.

Em suma, por essa perspectiva, abre-se espaço a saberes e aspectos pouco relevados até então: as Ciências Humanas, a ética e a eqüidade ${ }^{5}$ - ao dar 
ênfase ao desenvolvimento e à utilização da tecnologia, articulada a um pensamento que compreende a natureza biopsicossocial e intersetorial da saúde. Suas intervenções resultam em alterações globais dos conteúdos, processos e das relações, caracterizando uma metamorfose profunda na educação médica, principalmente na esfera dos valores - a qual já se encontra no projeto pedagógico do curso de medicina mencionado anteriormente.

o corpo biomédico e o encontro intercultural

Ainda que todas essas mudanças na formação médica no país apontem para momentos distintos de sua história, é preciso problematizar a realidade objetificada pelo saber médico desde sua constituição enquanto saber disciplinar: o corpo. Esta discussão pode oferecer uma reflexão mais profunda, no sentido de atingir bases epistemológicas do referido conhecimento e facilitar o alcance das diretrizes ideológicas e pedagógicas atuais.

Michel Foucault muito nos ensina nessa empreitada. Em O Nascimento da Clínica (1963), investiga a positividade do saber médico moderno, a partir de seus objetos, conceitos e métodos, bem como da elaboração de seus princípios biológicos. Contudo, a obra não se limita a uma inter-relação conceitual de saberes que demonstra como o conhecimento da doença, considerada essência abstrata, cede lugar a um saber moderno sobre o indivíduo num corpo doente. $\mathrm{O}$ autor articula os saberes com o extradiscursivo, ou seja, com instituições como o hospital, a família, a escola e as transformações político-sociais. Afinal, o saber sobre o doente, associado às práticas institucionais do internamento, mostrou-se mais relevante do que o saber teórico.

Foi justamente a ação sobre o corpo, o adestramento do gesto, a regulação do comportamento e a normalização do prazer, além da interpretação do discurso, com o objetivo de separar, comparar, distribuir, avaliar, classificar e hierarquizar, que levaram ao surgimento desta figura singular, individualizada: o ser humano. Sem dúvida, resultado da produção do poder e objeto de saber médico, em especial. Conforme aponta Machado (1996), Foucault introduziu nas análises históricas a questão do poder como um recurso capaz de explicar a produção dos saberes que intervêm materialmente, atingindo a realidade mais concreta dos indivíduos - o corpo - e desencadeando o moderno processo de individuação.

Foi exposto, assim, um poder singular, nomeado disciplina ou poder disciplinar, que atua feito uma rede sem núcleos centrais ou fronteiras, fabricando o tipo de ser humano, de força de trabalho, imprescindível ao funcionamento e à manutenção da sociedade capitalista, submissa a sua dominação política e produtora com o máximo de rapidez e eficácia. Trata-se de técnicas, dispositivos ou mecanismos de poder, configurando-se como "métodos que permitem o controle minucioso das operações do corpo, que asseguram a sujeição constante de suas forças e lhes impõem uma relação de docilidade-utilidade..." (Foucault, 1987, p.180). Além de serem inter-relacionadas, essas técnicas adaptam-se às necessidades específicas de diversas instituições que, cada uma a sua maneira, realizam um objetivo similar, quando consideradas do ponto de vista político. 
Ressalta-se, ainda, que a vigilância contínua, perpétua e permanente é um dos seus principais instrumentos de controle, em particular nos espaços institucionalizados, nos quais ocorre por meio de todos os agentes institucionais. Esta vigilância impregna quem é vigiado de tal modo que este adquire de si mesmo a visão controladora de quem o olha. Soma-se a isto o fato de que a disciplina implica um registro contínuo do conhecimento, pois elabora um saber ao exercer o poder, extraindo do próprio exercício seu aprimoramento.

Por meio desses ensinamentos foucaultianos, podemos observar que não apenas os excessivos conteúdos de natureza anátomo-fisiológica como os rituais acadêmicos cotidianos conformam o futuro profissional em saúde, adequando-o para esquadrinhar, seccionar, observar pontualmente e moldar indivíduos a serem medicalizados. Ou seja, promovem, em conjunto, a separação do olhar técnico-especializado, com sua ação discursiva sobre a doença, das demais dimensões da experiência humana. Concomitantemente, contribuem para a construção dos corpos médicos disciplinados. O saber médico acaba por ser concebido e seu discurso enunciado como independentes do corpo que os produzem, superiores ao restante da vivência humana, bem como preparados para se dirigirem a órgãos e tecidos em si, absolutizados e isolados de um sistema mais amplo, de uma história pessoal, de uma cultura e de relações político-sociais.

Nesse modelo tradicional, nada se aproveita do encontro humano e do saber iniciático, que uma relação com pretensão terapêutica pode proporcionar para todos os sujeitos nela envolvidos. Trata-se de uma relação hierárquica em que o poder se estabelece pela assimetria dos termos, reproduzindo, nos consultórios e hospitais, a mesma relação entre a autoridade ativa do professor e a passividade dos alunos, entre aquele que tudo sabe e o que nada sabe, entre a verdade objetiva enunciada pelo professor e sua procura no exame dos corpos nus pelo futuro médico. Desse modo, não há troca que não seja mercantil entre os implicados no encontro, o que restringe as chances de também promover algum tipo de auto-conhecimento, de ampliação da consciência, de aprendizado libertador e de cura ao médico: a possibilidade dialógica de se ver no outro e de se humanizar com ele.

Muito tem a contribuir nessa direção a tradição antropológica que busca, na alteridade, a compreensão e o alargamento da visão de mundo e do ethos ocidental. Segundo Pereira (1993), o encontro intercultural pode ter efeitos transformadores sobre as estruturas de pensamento em jogo, levando-as ao exercício da autocrítica. Para argumentar a respeito, a autora serve-se justamente de casos etnográficos nos quais a noção biomédica de corpo sofre um processo de "desnaturalização", ao defrontar-se com culturas que não

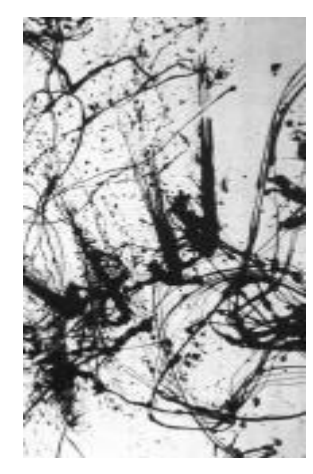
fragmentam o corpo e que não o consideram metáfora do desejo ou portador de uma verdade. Perante outros povos, deparamo-nos com o corpo fenomenal, sem materialidade e objetividade, sem ser suporte de identidade e autonomia pessoal.

Pereira (1993) lembra, ainda, que tal processo de desnaturalização de nossas categorias vem sendo realizado por pares ao romperem com a filosofia clássica (como vimos com Foucault), tanto que podemos aproximar suas proposições de construções mentais não-ocidentais. Ou seja, ela resgata a 
deconstrução derridariana e a deleuziana para apontar a necessidade de se implodir os esquemas duais hierárquicos, formadores da nossa civilização locus de poder, para Baudrillard (1979). Vê-se, então, a multiplicidade no lugar da dualidade; a contigüidade, a metonímia $e$ a fusão no lugar da cisão $e$ da oposição.

Merleau-Ponty é também evocado pela autora para deixar claro o entrelaçamento entre sujeito e objeto, fazendo desaparecer a oposição ativo/ passivo. Emerge, assim, o entrelaçamento que une aquele que toca e o que é tocado, o olhar e a coisa vista, a teoria e o mundo. De modo curioso, o elo por excelência, que supera o afastamento entre os pólos e realiza a reciprocidade entre eles, é justamente a carne. Afinal, esta "é o único meio que possuo para chegar ao âmago das coisas, fazendo-me mundo e fazendo-as carne", pois, "onde colocar o limite do corpo e do mundo, já que o mundo é carne?" (Merleau-Ponty, 1971, p.134).

Nesse exercício antropológico de nos aproximar do outro, tornando-o familiar, e, simultaneamente, afastando-nos de nossa experiência, desnaturalizando-a ao exotizá-la, podemos perceber o quanto é necessário que a formação médica inovadora reformule suas concepções sobre o corpo. $\mathrm{O}$ médico deve problematizar sua própria experiência corporal, integrá-la a seu saber e a seu olhar, bem como deve esforçar-se em ir ao encontro dos corpos singulares que para ele se apresentam. Contudo, para isto, é fundamental que novas práticas pedagógicas dêem conta de abarcar essa mudança de paradigma.

\section{Notas sobre uma Pedagogia de Resistência}

\section{Pressupostos teóricos}

Para examinar o modelo que vem sendo proposto como alternativa ao tradicional ensino da medicina, será preciso lembrar rapidamente a situação atual, tentando extrair daí a teoria pedagógico-psicológica que o informa. Trata-se de uma situação bem conhecida: a presença de um grupo de alunos sentados diante de um professor, que, em geral, é um especialista que fala, enquanto os alunos escutam, buscando preencher suas questões, mal formuladas, obscuras, com as luzes que vêm do Mestre. Essa pedagogia já foi analisada por Paulo Freire, que a chamou de educação bancária, e seu traço característico é o da passividade/ignorância do aluno perante a atividade/ autoridade do professor.

O objetivo de realizar a desnaturalização desse método exige, entretanto, que se apreenda a concepção de mundo que ele veicula, no que concerne às relações entre os humanos e como estas vêm refletir em seus corpos, em seus processos de subjetivação e de individuação, assim como em sua presença no meio social. Recorreremos, para tal, ao texto clássico de Platão (O Banquete) e a sua interpretação contemporânea realizada por Lacan (1991), na qual a idéia que subjaz é a do modelo transferencial, que se manifesta nas diversas relações humanas, principalmente naquelas que envolvem o exercício da aprendizagem.

A transferência, como o amor, relaciona-se com a questão do saber. A relação entre os personagens de $O$ Banquete, Sócrates e Alcibíades, é da ordem mestre-discípulo, visando à educação desse último. Mas, ao mesmo tempo, trata-se de uma relação erótica. Alcibíades declara amar Sócrates, na medida em

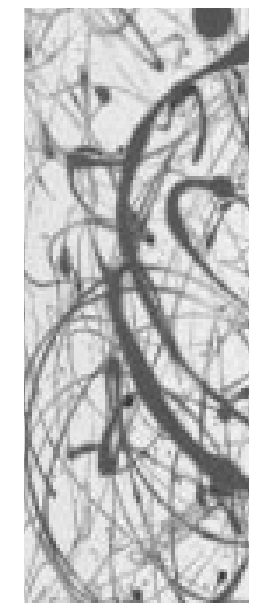


que este possui o agalma, algo que, embora escondido, torna-o sujeito suposto saber, objeto de desejo do discípulo. Este último, sujeito suposto não saber.

Sócrates se furta a dar sinal de seu desejo por Alcibíades porque sabe que o desejo de Alcibíades é o seu saber. Ou seja, Sócrates se recusa a ser objeto de amor porque se coloca na posição de sujeito, de desejante, e espera que Alcibíades, ao perceber nele uma atitude positiva com relação ao conhecimento, sinta-se reconhecido em seu desejo.

Assim deveria ocorrer em uma relação de aprendizagem: o aluno vê no professor o portador de um saber que o faria se sentir enriquecido, reconhecido como desejante de saber mais. Cabe ao professor, como coube a Sócrates diante da demanda de Alcibíades, abster-se de toda atitude compreensiva e agir com neutralidade e silêncio, levando o aluno a perceber que deve buscar, como ele, o conhecimento, instaurando sua própria diferença $e$ autonomia em relação ao professor.

O desejo, nessa perspectiva, por ter sido gerado pela conjunção de Pênia (isto é, falta, miséria, aporia) com Poros (riqueza, plenitude), tem, na sua constituição, a marca da falta, que passa a ser o único motor que nos leva a uma busca incessante. No caso da aprendizagem, tal falta se manifestaria enquanto consciência da ignorância, que faz com que deslizemos de um objeto de saber a outro, visando sempre algo que está além do já sabido, o objeto interdito, impossível. Nesse processo, tornamo-nos humanos, sujeitos que se movem numa estrutura de relações hierarquizada, na qual alguns portam, ainda que provisória e ilusoriamente, o saber, enquanto outros tudo ignoram $e$ só vão sair dessa ignorância se puderem liquidar a relação transferencial que os infantiliza e domina.

Apesar disso, é um modelo que tem perdurado e se manifesta nas relações humanas de variadas formas. Seu vigor talvez resida no fato de ter sido naturalizado e transformado numa espécie de essência do humano, naquilo que este tem de mais obscuro e que constitui sua pergunta primordial: como lidar com a imprevisibilidade do mundo, dos outros e de nós mesmos? A esta pergunta, a resposta da falta, enquanto fundante do desejo, parece ser a única possível. No entanto, não o é.

Em outra perspectiva, a de Espinosa (1979), o desejo não tem uma falta anterior que o funda. Ele é positividade em função da qual o homem persevera em seu ser. Não é que algo falte e, então, torna-se desejável. Mas é o desejo que, na sua força criadora, disponibiliza o que já existe, abre novos campos de possível, conforme diriam Deleuze \& Guattari (1974), inspirados nesta teoria. $\mathrm{O}$ desejo, aqui, torna-se produtor, "máquina desejante". Desde esse ponto de vista, o objeto interditado, que funda o desejo na falta, torna-se distorção operada pela repressão social ao fluxo subversivo do desejo.

Se o desejo cria o objeto e é sempre produção, é também ele que cria a realidade da relação professor/aluno. Esta pode tanto ser construída à maneira da falta, por meio de uma disciplina do desejo que rouba ao aluno sua produtividade, seu olhar singular sobre o mundo, como pode ser construída à maneira da positividade deleuziana, dando espaço à criação de "novos blocos de possivel' (Guattari, 1986).

A restituição da fala e do potencial produtivo ao aluno seria um novo campo 
do possível, talvez o mais decisivo deles no processo de constituição do saber. Supõe-se, aí, não uma falta de saber do aluno, mas um saber silenciado, ao qual se deve dar voz. Essa pequena mudança é suficiente para possibilitar que cada um maximize seu potencial criativo em cada situação que vive. Para tanto, é preciso recusar a ligação do desejo a algo sempre situado além do apreensível por nós. É justamente esta volta do desejo em direção a um além, indisponível, que está na base de todo pensamento autoritário.

Assim, não tendo o aluno projetado no professor nenhum ideal de si mesmo, a este caberia a função de testemunhá-lo no acesso à fala, de fazê-lo exprimir o que já pensava, de disponibilizar, de criar "novos blocos de possível". O professor seria, assim, o criador de situações inusitadas, inesperadas, para além dos códigos previamente conhecidos pelo aluno.

O projeto do curso de Medicina do GDF

O projeto pedagógico que norteia o curso de medicina do GDF, que ora analisamos, parece tentar recusar o modelo do desejo baseado na falta $e$ permanecer, ainda que sem ter plena consciência desta proposição, fiel ao modelo do desejo enquanto positividade. Podemos constatar isto não apenas no projeto pedagógico em si, mas também nos textos e relatórios de avaliação que norteiam seus eixos e suas inovações, como por exemplo, Belaciano (1996) e Costa Neto (2000), além de documentos como a Avaliação do Ensino Médico no Brasil: Relatório Geral 1991, da Comissão Interinstitucional de Avaliação do Ensino Médico (1997), e a Avaliação das Condições de Oferta de Cursos de Graduação - Matemática, Medicina. Relatório - Síntese I, do MEC/SESU/DEDES (Brasil, 2000).

Desse modo, sua metodologia, além de ser centrada no aluno e orientada à comunidade, é construída segundo a idéia da "Aprendizagem Baseada em Problemas - ABP” (Berbel, 1994, 1996a, 1996b; Holmes \& Kaufman, 1994), na qual os alunos são os responsáveis pela busca de respostas às questões que lhes são expostas. Sendo, então, o agente principal da dinâmica ensinoaprendizagem, o aluno tem oportunidade de se ver em situações significativas, contextualizadas e do mundo real, motivadoras da busca por conhecimentos $e$ habilidades para resolver problemas.

Tais características da dinâmica de ensino-aprendizagem aproximam o método ABP da pedagogia crítica de Paulo Freire (1970, 1991, 1992), segundo a qual a educação libertadora só se realiza na medida em que engaja a consciência crítica e o desejo de autonomia dos estudantes no processo educativo, sempre presentes na concretude de sua experiência e história de vida e não tomados como sujeitos idealizados. Trata-se, também, de um processo permanente de indagação e discussão dos dilemas do seu meio e do seu tempo, bem como da inserção crítica em tais problemáticas.

No curso de medicina em questão, o método $A B P$ se efetiva da seguinte forma: oito estudantes são reunidos em um grupo tutorial, coordenado por um tutor, que mantém necessariamente um vínculo profissional com a rede pública de saúde. Sua função é, ao invés de transmitir saber, levar os alunos a criar soluções e a fornecer hipóteses de diagnósticos - processo no qual são obrigados a se confrontar com suas próprias experiências, seus corpos e os corpos alheios, suas falhas e deficiências, criando seu método e ritmo de 
estudo. Os alunos se empenham em buscar respostas usando diversos recursos, desde conversas com professores e profissionais, pesquisas em bibliotecas tradicionais, até a utilização de laboratórios, atuação em ambulatórios, experiência em hospitais e comunidades.

Para tal, são inseridos em diversas atividades de saúde a partir do seu ingresso no curso, estimulados a realizar seus trabalhos e estudos em grupo, bem como em cooperação interdisciplinar e multiprofissional. Paralelamente a esta dinâmica da Aprendizagem Baseada em Problemas, os alunos são capacitados no eixo pedagógico "Habilidades e Atitudes" em laboratórios de habilidade, no qual elaboram conhecimentos em semiologia, comunicação, procedimentos médicos, entre outros. Além disso, no que se refere às práticas profissionais que devem adquirir, o ensino é integrado aos serviços da rede pública de saúde prestados às comunidades do Distrito Federal.

Finalmente, nesse eixo de formação, denominado Interação Ensino Serviço $e$ Comunidade (IESC), os alunos desenvolvem a capacidade de compreender a realidade da saúde em interação cotidiana com o contexto em que se insere a população atendida pelo serviço de saúde do GDF e em equipe multidisciplinar. A base para esta atividade encontra-se num modelo de atenção à saúde cujo enfoque do atendimento é a família - centro do universo de relações sociais da grande parte dos grupos que estão à margem ou ingressaram parcialmente no processo de individuação moderna.

Por este prisma, então, procura-se romper com as tradicionais concepções do corpo biomédico, uma vez que o corpo "em família" apresenta-se humanizado, longe de ser mera força de trabalho, pois está inserido em uma teia de afetos e conflitos, em histórias e em complexas estruturas político-sociais. Esse corpo demanda um outro olhar e sua queixa uma outra escuta para se efetivar o diagnóstico e a cura, o que exige uma troca plena de saberes.

No entanto, as observações levantadas até o momento apontam várias dificuldades na implementação desses princípios que estariam na base do projeto pedagógico da Escola de Ciências da Saúde do GDF. Dentre elas, pode-se citar as barreiras à inserção das reflexões oriundas das Ciências Humanas nos temas dos grupos tutoriais, os quais facilmente caem reféns dos discursos tradicionais sobre o corpo e sobre a relação saúde/doença. Isso se deve, principalmente, à impregnação, pelos atores da educação médica, de um imaginário social que concede ao saber médico tradicional o lugar privilegiado de produção da verdade. Tal imaginário, impregnado e expresso na formação desses tutores/facilitadores/médicos, encontra-se refletido tanto no seu comportamento diante dos alunos quanto no destes últimos, cuja motivação para a escolha da medicina é muitas vezes a atração por essa posição de poder/ saber conferida pelo ofício da medicina.

Possivelmente, decorre ainda desse imaginário a refração encontrada entre os estudantes no que diz respeito às abordagens críticas que as Ciências Humanas aportam à problemática da medicina, mostrando a relação do corpo com a cultura, com a sociedade e com trajetórias individuais. Tais conhecimentos, nomeados genericamente de "psicossociais", são tratados como de menor importância, sendo vistos na condição de complementares aos "verdadeiros" e "supervalorizados" conhecimentos médicos de base exclusivamente biológica. 
Vários outros problemas, relacionados às dificuldades encontradas pelos estudantes no contato direto com as populações-alvo, que são, em geral, de baixa renda, periférica e constituída por boa parte de excluídos. Provavelmente, tais problemas surgem em decorrência da diferença extrema de linguagem e de cultura entre esses dois grupos, conforme temos observado em nossas investigações. No entanto, o fato de o estudo estar ainda em curso exige a postergação de uma análise mais aprofundada da questão.

Por ora, salienta-se que tais reflexões críticas não deverão se ater apenas ao curso pesquisado, uma vez que o próprio método ABP tem sido avaliado $e$ criticado por alguns pedagogos, profissionais e professores (por exemplo, a breve análise feita por Soares, 2003), os quais nos apontam para a necessidade de pensarmos e investigarmos em suas direções. Desse modo, no que concerne a sua eficácia pedagógica libertadora, resta-nos ainda tirar as conseqüências teórico-metodológicas que contribuam para uma possível reconstrução do método, o que se pretende indicar ao final dessa pesquisa na forma de subsídios ao projeto pedagógico do referido curso.

Assim, o que se poderia frisar no momento é a importância de se insistir na busca de um diálogo intercultural efetivo, com o objetivo de fazer emergir novos princípios e conceitos para a medicina, concepções mais libertadoras de aprendizado e diversas práticas curativas de sujeitos desejantes. Trata-se de um desafio rumo a uma verdadeira e profunda reforma educacional, na qual sejam rejeitados os esquemas mentais autoritários, mercantilistas e fragmentados.

\section{Referências}

ALMEIDA, M. Educação médica e saúde: possibilidades de mudança. Londrina: Ed. UEL, Rio de Janeiro: ABEM, 1999.

BAUDRILLARD, J. De la seduction: I'horizon sacré des apparences. Paris: Galilée, 1979.

BELACIANO, M. I. O SUS deve aceitar este desafio: elaborar proposições para a formação e capacitação de recursos humanos em saúde. Revista Divulg. Saúde Debate, n.12, p.29-33, 1996.

BERBEL, N.A.N. Currículo médico e compromisso social. Revista Divulg. Saúde Debate, n.9, p.59-64, 1994.

BERBEL, N.A.N. Metodologia da problematização no ensino superior e sua contribuição para o plano de práxis. Rev. Semina, v.17, ed. esp., p.7-16, 1996a.

BERBEL, N.A.N. Metodologia da problematização: uma alternativa metodológica apropriada para o ensino superior. Rev. Semina, v.16, ed. esp., p.9-19, 1996b.

BRASIL. Ministério da Educação. SESU. DEDES. Avaliação das condições de oferta de cursos de graduação - matemática, medicina. Relatório - Síntese I. Brasília, 2000.

COMISSÃO INTERINSTITUCIONAL NACIONAL DE AVALIAÇÃO DO ENSINO MÉDICO. Avaliação do Ensino Médico no Brasil: Relatório Geral 1991 - 1997. Brasília, 1997.

COSTA NETO, M. M. O currículo médico e o sistema de saúde em construção. Saúde Família, p.46-51, jul., 2000.

DELEUZE, G.; GUATTARI, F. El antiedipo: capitalismo y esquizofrenia. Trad. Francisco Monge. Barcelona: Barral Editores, 1974.

ESPINOSA, B. Ética. In: CHAUI, M. (Trad.) Espinosa. São Paulo: Abril Cultural, 1979. p.71-301. (Os Pensadores). 
FERREIRA, J. R.; COELHO NETO, A.; COLLADO, G. B.; LINGER, C.; LUNA, R.; PARCALLAS, D. El análisis prospectivo de la educación médica en America Latina. Educ. Méd. Salud, v.22, n.3, p.9-18, 1988.

FOUCAULT, M. O nascimento da clínica. Petrópolis: Vozes, 1963.

FOUCAULT, M. Vigiar e punir: nascimento da prisão. Petrópolis: Vozes, 1987.

FREIRE, P. Pedagogia do oprimido. São Paulo: Paz e Terra, 1970.

FREIRE, P. A educação na cidade. São Paulo: Cortez, 1991.

FREIRE, P. Pedagogia da esperança: um reencontro com a pedagogia do oprimido. Rio de Janeiro: Paz e Terra, 1992.

GUATTARI, F.; ROLNIK, S. Cartografias do desejo. Petrópolis: Vozes, 1986.

HOLMES, D.B.; KAUFMAN, D.M. Tutoring in Problem-Based Learning: a teacher development process. Med. Educ., n.28, p.275-843, 1994

LACAN, J. Le transfert. In: LACAN, J. Le seminaire, livre VIII. Paris: Seuil, 1991.

MACHADO, R. Por uma genealogia do poder. In: FOUCAULT, M. Microfísica do poder. Rio de Janeiro: Graal, 1996. p.7-23.

MERLEAU-PONTY, M. O visível e o invisível. São Paulo: Perspectiva, 1971.

PEREIRA, O. A desconstrução/reconstrução do corpo no espaço transcultural. Universa, v.2, n.2, p.25968, 1994.

SOARES, V. PBL: modismo ou revolução nos cursos de medicina? Diálogo Médico, p.16-7, maio/jun., 2003.

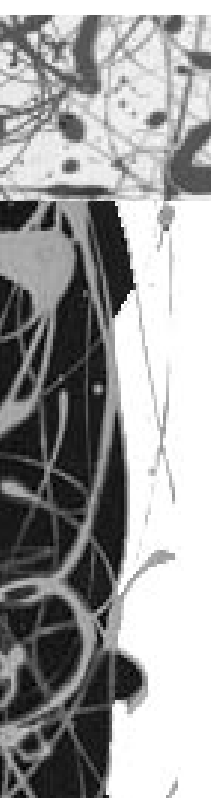

PEREIRA, O. P.; ALMEIDA, T. M. C. La formación médica según una pedagogía de resistencia, Interface - Comunic., Saúde, Educ., v.9, n.16, p.69-79, set.2004/fev.2005.

En este artículo se discute el estado actual de las prácticas educativas relativas a la salud y la visión fragmentaria que éstas tienen del ser humano, al reducirlo a un cuerpo técnico, pasivo, objeto de intervenciones invasivas y medicamentosas. Tales prácticas, al excluir de su horizonte de referencia la dimensión totalizante del ser humano, dejan de abordar los rasgos sociales, culturales, políticos y psicológicos presentes en los estados de salud/enfermedad. Además, dichas prácticas desconocen la subjetividad de los personajes involucrados en la producción de la enfermedad y de la propia cura, así como se desconocen a sí mismas como artífices del modelaje de un tipo propio de subjetividad individualista moderna. De este modo se presenta una visión crítica de la excesiva biologización de la educación dominante, surgida en el interior de algunas escuelas de salud y que se nutre del saber de las Ciencias Humanas. Finalmente, se indican directrices teórico-metodológicas para una propuesta alternativa de educación médica que considera al ser humano en su globalidad, alteridad y condición de sujeto de su propia historia, y que rompa con las estructuras conservadoras, autoritarias y mercantilistas de la formación médica actual.

PALAVRAS CLAVE: Formación médica; pedagogía crítica; cuerpo y dialogo intercultural. 


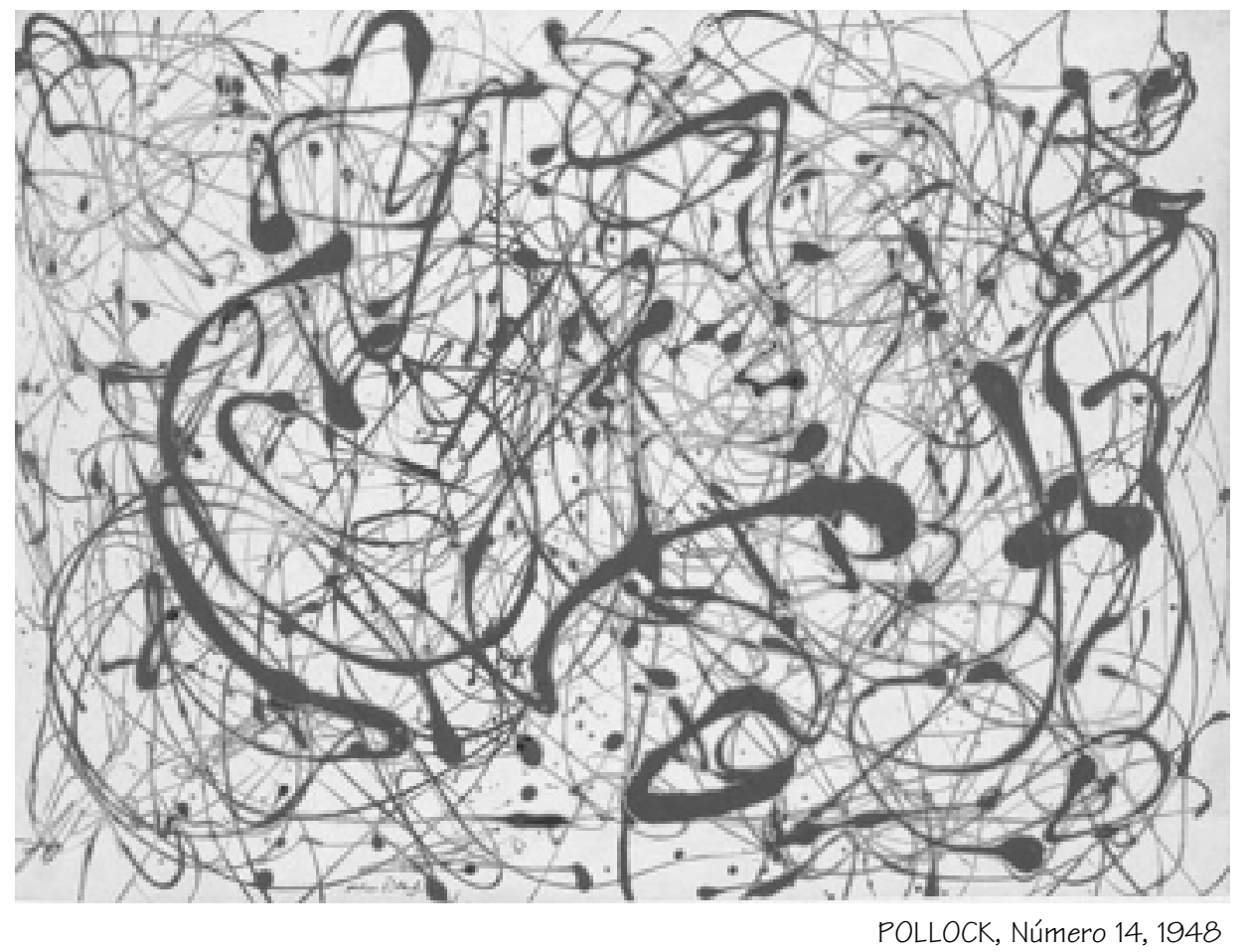

80 Interface - Comunic, Saúde, Educ, v.9, n.16, p.80, set.2004/fev.2005 